\title{
Expression of EPSP/Spike Potentiation Following Low Frequency and Tetanic Stimulation in the CA1 Area of the Rat Hippocampus
}

\author{
C. Bernard and H. V. Wheal \\ Department of Physiology and Pharmacology, University of Southampton, Southampton SO16 7PX, United \\ Kingdom
}

\begin{abstract}
Low frequency stimulation (LFS, $1 \mathrm{~Hz}$ for $15 \mathrm{~min}$ ) has been shown to produce an NMDA receptor dependent homosynaptic long-term depression (LTD) of synaptic potentials in the CA1 area of the rat hippocampus. Here we describe experiments aimed at characterizing EPSP/spike (E/S) coupling associated with this form of LTD. Our data show that following LFS neurons have a higher probability of synchronous discharge in response to a population EPSP of fixed slope (E/S potentiation). This E/S potentiation was not significantly enhanced by a tetanic stimulation. When the protocol was reversed, that is, starting with a tetanic stimulus, E/S potentiation was observed which was unaffected by a subsequent LFS. Saturating these synaptic responses to either a maximal or a minimal value produced similar effects on E/S coupling. E/S depression was never encountered. Finally, we found that the expression of E/S potentiation did not require the activation of NMDA receptors. These data suggest that at the level of a local neuronal network in the CA1 area, LFS is not a very powerful tool since the synaptic depression is associated with a potentiation of the population response of these neurons. Furthermore, the expression of E/S dissociation seems different from that of homosynaptic long-term potentiation and LTD.
\end{abstract}

[Key words: synaptic plasticity, long-term potentiation, long-term depression, hippocampus, EPSP/spike coupling, NMDA receptors]

There has been considerable interest in the role of the hippocampal formation in learning and memory. The role of synaptic plasticity is a fundamental issue in our understanding of these processes (Hebb, 1949). Both long-term potentiation (LTP, see Bliss and Collingridge, 1993) and long-term depression (LTD, see Dudeck and Malenka, 1994) at excitatory synapses contribute to the computational requirements of learning processes. By playing with the protocols used to induce LTP and LTD it has been shown that excitatory synaptic responses could be potentiated and depressed in succession (Dudeck and Bear, 1992; Mulkey and Malenka, 1992; Dudek and Bear, 1993), suggesting common mechanisms of induction (Dudek and Bear, 1993; Mulkey et al., 1993). It is obvious that any long-term modifi-

Received Feb. 9, 1995; revised Apr. 17, 1995; accepted May 8, 1995.

This work was supported by the Wellcome Trust, British Council and the Foundation Simone et Cino del Duca.

Correspondence should be addressed to Professor Howard Wheal, Department of Physiology and Pharmacology, University of Southampton, Bassett Crescent East, Southampton SO16 7PX, United Kingdom.

Copyright (C) 1995 Society for Neuroscience $0270-6474 / 95 / 156542-10 \$ 05.00 / 0$ cation of the synaptic event will change the output of the neuron in response to a given excitatory input. As a consequence there will be a change in the pattern of discharge of the cell.

However, from an information processing point of view, other parameters are also contributing to the control of the cells firing properties. These include the inhibitory circuitry as well as the threshold of the action potential. The modification of either of these parameters independently from plasticity at the excitatory synapses will satisfy the computational requirements for learning and memory. However, to date, there have been very few studies designed to investigate a specific role for these parameters. Associated with the production of LTP was the phenomenon called EPSP/spike (E/S) potentiation (Douglas and Goddard, 1975; Andersen et al., 1980; Wilson, 1981; Wilson et al., 1981; Abraham et al., 1987; Kairiss et al., 1987; Frey et al., 1988; Taube and Schwartzkroin, 1988a; Taube and Schwartzkroin, 1988b; Chavez-Noriega et al., 1989; Reymann et a1., 1989; Hess and Gustafsson, 1990; Chavez-Noriega et al., 1990; Tomasulo et al., 1991; Guo et al., 1992; Tomasulo and Ramirez, 1993). E/S potentiation was characterized by the fact that the population spike amplitude (PSA) increased more than could be accounted for by changes in the slope of the population EPSP (popEPSPS). As a consequence, if the slopes of the population EPSPs are matched before and after the conditioning stimulus the amplitude of the population spike will have increased. Two nonexclusive mechanisms have been proposed to explain this phenomenon: a decreased inhibitory drive (Wilson, 1981; Wilson et al., 1981; Abraham et al., 1987; Kairiss et al., 1987; Chavez-Noriega et al., 1989, 1990; Hess and Gustafsson, 1990; Tomasulo et al., 1991; Tomasulo and Ramirez, 1993) and/or a modification of the firing threshold (Schwartzkroin and Prince, 1980; Taube and Schwartzkroin, 1988a,b; Hess and Gustafsson, 1990). In common with LTP, E/S potentiation reinforces the synaptic and cellular events leading to a higher probability of their synchronous discharge. Recently, low frequency stimulation (LFS) of the afferents to CA1 pyramidal cells was found to produce homosynaptic LTD (Dudeck and Bear, 1992; Mulkey and Malenka, 1992; Dudek and Bear, 1993). However, the coupling between the synaptic and cellular events has not been studied following LFS.

In this study we describe experiments in the CA1 area of the rat hippocampus designed to characterize $\mathrm{E} / \mathrm{S}$ dissociation following LFS. We have addressed four issues. First, what is the effect of LFS on E/S coupling. Second, what happens if the synaptic response is potentiated before the induction of LTD. Third, what changes in E/S coupling occur following saturation of the synaptic response. Finally, we addressed the question of 
whether the expression of $\mathrm{E} / \mathrm{S}$ dissociation is dependent on the activation of NMDA receptors. Our results suggest that synaptic LTD is associated with E/S potentiation. This means that despite the decreased synaptic efficacy the pyramidal cells have a higher probability of synchronous discharge. Furthermore, the E/S potentiation was usually maximum following the first conditioning stimulus be it a tetanic stimulation (TS) or a LFS train. Finally, $\mathrm{E} / \mathrm{S}$ potentiation occurred even when the NMDA receptors were blocked with D-2-amino-5-phosphonovalerate (D-APV) during LFS, suggesting that it is an NMDA-independent phenomenon.

\section{Materials and Methods}

Adult male Wistar albino rats (200 gm, 6 weeks old) were anesthetized with halothane before decapitation and removal of the brain. Both hippocampi were removed, placed in ice cold $\left(4^{\circ} \mathrm{C}\right)$ artificial cerebrospinal fluid (ACSF, $\mathrm{pH} 7.4)$ and then sliced $(400 \mu \mathrm{m})$ with a McIlwain tissue chopper. Slices were incubated in ACSF for at least $1 \mathrm{hr}$ at room temperature before being placed in a subfused in vitro slice chamber. The medium was equilibrated with gaseous mixture of $95 \% 0_{2}$ and $5 \% \mathrm{CO}_{2}$. The ACSF was composed of (in $\mathrm{mM}$ ) NaCl, $124.0 ; \mathrm{KCl}, 3.3 ; \mathrm{KH}_{2} \mathrm{PO}_{4}$, 1.3; $\mathrm{NaHCO}_{3}, 26 ; \mathrm{MgSO}_{4}-7 \mathrm{H}_{2} \mathrm{O}, 1.0 ; \mathrm{CaCl}_{2}, 2.5$ and D-glucose, 10 . The temperature in the recording chamber was maintained at $30-32^{\circ} \mathrm{C}$.

Extracellular population spikes (PSs) and population EPSP (popEPSP) were recorded in stratum pyramidale and stratum radiatum respectively using 5-10 M $\Omega$ resistance glass microelectrode filled with 3 $\mathrm{M} \mathrm{NaCl}$. Bipolar twisted-wire stimulation electrodes (trimel insulated apart from $50 \mu \mathrm{m}$ at the tip) were placed in the stratum radiatum of CA1 area proximally to stratum pyramidale near the recording electrodes $(200-500 \mu \mathrm{m})$. Stimuli in the form of $10-40 \mu \mathrm{sec}$ pulses, 5--50 $\mu \mathrm{A}$ in amplitude were delivered at $30 \mathrm{sec}$ intervals. The viability of the slices was tested using a paired pulse stimuli with an interpulse interval of $20 \mathrm{msec}$. All slices showed paired pulse inhibition.

Tetanic stimuli were applied through the same bipolar electrode and consisted of four trains of 10 shocks at $100 \mathrm{~Hz}$ every 1 sec. LFS consisted of a train of 900 shocks at $1 \mathrm{~Hz}$. Population spike amplitudes (PSA) were measured as the distance between the peak negativity and the line joining the two positivities of the PS. Population EPSP slopes (popEPSPS) were measured as the initial slope taken during the first $0.2 \mathrm{msec}$ after their onset. Changes in the popEPSPSs and/or the PSAs were considered as long-term if they were sustained for $30 \mathrm{~min}$ or longer. The stimulus intensity that induced a PS of $75 \%$ of maximum amplitude was used as the test and conditioning stimulus. The amplitude of the presynaptic volley was monitored throughout the experiments and was seen to be stationary.

In these experiments, full input/output $(\mathrm{I} / \mathrm{O})$ curves were constructed before and $30 \mathrm{~min}$ after all conditioning stimuli. E/S curves were then plotted from these $1 / O$ curves. The popEPSPSs and PSAs were plotted on the abscissae and ordinate, respectively.

All data were digitized on line using a 16 bit $\mathrm{A} / \mathrm{D}$ converter sampling at $20 \mathrm{kHz}$. These data were stored on optical disk and analyzed using a program for evaluation of extracellular electrophysiological data. $\mathrm{Pa}$ rameters were compared with a Student's $t$ test. All values are expressed as mean $\pm \mathrm{SD}$.

D-2-Amino-5-phosphonovalerate (D-APV) was obtained from Tocris Neuramin, Bristol, England. D-APV was dissolved in distilled water and then diluted in ACSF to the desired concentrations and oxygenated ( $\mathrm{pH} 7.4$ ) before being perfused into the bathing medium.

\section{Results}

\section{Effect of LFS on naive preparations}

Figure 1 illustrates the effects of LFS on both popEPSPSs (Fig. $1 A$ ) and PSAs (Fig, 1B). As previously reported (Dudeck and Bear, 1992, 1993; Mulkey and Malenka, 1992), LFS produced stable depression of the synaptic event to $47 \%$ of its initial control value (Fig. $1 A, C I-3$ ). There was a parallel long-term decrease (LTd) of the PSA to $65 \%$ of its control response (Fig. $1 B, C 46$ ). However, these two values were not sufficient to determine whether or not there was a strict correspondence between these depressions. In order to make the appropriate comparison, we adjusted the stimulus intensities after the con- ditioning stimulus to produce an identical slope to the popEPSP as in the control. Despite identical popEPSPSs, the corresponding PS had increased in amplitude when compared with the control (Fig. 1D). We then plotted the PSAs as a function of the popEPSPSs obtained at all stimulus intensities both before and after LFS (Fig. 1E). There was a clear left shift of the E/S curve following LFS, indicative of E/S potentiation. Thus, the synaptic LTD was partly counterbalanced by the higher probability of synchronous discharge of the CA1 neurons.

LTD and LTd of the popEPSPSs and PSAs respectively were reversed by subsequent TS. Thirty minutes following LFS, TS resulted in both synaptic LTP (77\% of control, Fig. $1 A, C 1-3)$ and a long-term increase (LTi) of the PSA ( $100 \%$ of control, Fig. 1B,C4-6). The TS also induced a further left shift of the E/S curve (Fig. $1 E$ ), suggesting that the parameters responsible for the potentiation had not saturated by the first conditioning stimulus. Data of all experiments $(n=10)$ are summarized on Figure $1 F$. Following LFS popEPSPSs were $66 \pm 18 \%$ of control values whereas PSAs were $73 \pm 12 \%$ of baseline responses. Subsequent TS resulted in potentiated popEPSPSs $(95 \pm 21 \%$ of control) and PSAs (112 $\pm 24 \%)$. In all cases LFS produced E/S potentiation. In five experiments, no additional left shift was observed. It should be noted that, as in previous studies, it was not possible to pool the E/S curves since each of them represent a unique example. However, for each experiment a popEPSP was evoked at a stimulus intensity to produce $75 \%$ of the maximum slope measured before LFS. The slope of this popEPSP was then matched with one obtained following LFS. The corresponding PSAs, before and after LFS, were measured. The difference between the two amplitudes was taken as a global index for any E/S shift. In these experiments the PSA measured following LFS was increased by $36 \pm 12 \%$.

As previously suggested the left shift of the E/S curve could be due to a decreased inhibitory drive and/or a modification of the firing threshold of the cells. To address this issue we measured paired pulse inhibition. In 6 out of 10 experiments, paired pulse inhibition was unchanged by LFS. In the other four cases paired pulse inhibition was decreased, that is, the PSA initiated by the second test pulse was greater than that observed before LFS (data not shown). However, these data were very difficult to analyze (see Discussion) and thus they have not been included in the study.

\section{Effect of LFS on previously potentiated responses}

The results on naive preparations led us to investigate the dynamic properties of E/S coupling. We thus tested the effects of LFS on slices where the synaptic responses had been previously potentiated. Figure 2 shows data from such an experiment where the initial TS conditioning resulted in both LTP of synaptic responses (124\% of control, Fig. $2 A$ ) and LTi of PSAs (141\% of control, Fig. $2 B$ ). TS also produced E/S potentiation (Fig. $2 D, E$ ). Both the LTP and LTi were reversed by a subsequent LFS ( $99 \%$ and $103 \%$ of control, respectively, Fig. $2 A, B$ ). However, no further changes in the E/S curve were observed following the second conditioning stimulus (Fig. $2 E$ ). Pooled data $(n=10)$ are summarized in Figure $2 F$. Following TS synaptic responses were $124 \pm 7 \%$ and PSAs were $140 \pm 12 \%$ of control. LFS reversed this effect by decreasing the potentials back to $102 \pm 6 \%$ and $95 \pm 9 \%$ of control, respectively. Following TS, E/S potentiation was observed in all experiments whereas in only four of these was there an additional left shift following LFS. The PSA measured following TS was increased by $32 \pm 9 \%$ when com- 
pared to that obtained before the conditioning stimulus (for matched popEPSPSs).

\section{Effect of saturation of synapses}

The previous data suggest that $\mathrm{E} / \mathrm{S}$ coupling may be close to saturation following the first conditioning stimulus be it LFS or TS. In order to test this possibility we saturated both the synaptic responses and the PSAs with multiple trains. Figure 3 shows an example where three successive LFS episodes, each separated by $5 \mathrm{~min}$, resulted in saturation of the depression of both the synaptic responses (44\% of control, Fig. $3 A$ ) and PSAs $(63 \%$ of control, Fig. $3 B$ ). However, a maximum leftward shift of the E/S curves had already occurred after the first LFS (Fig. 3C). As previously shown TS unsaturated the responses $(82 \%$ and $150 \%$ of control, respectively) but had no additional effect on the E/S curve. The results of this series of experiments $(n=4)$ are summarized on Figure $3 D$. Following the third LFS synaptic responses and PSAs were $42 \pm 7 \%$ and $61 \pm 9 \%$ of control, respectively. Following TS responses were $94 \pm 12 \%$ and 143 $\pm 15 \%$, respectively. Usually, the maximum $\mathrm{E} / \mathrm{S}$ potentiation was achieved after the second LFS and did not change following TS. The PSA measured following the second LFS was increased by $38 \pm 14 \%$ when compared to that obtained before the conditioning stimuli (for matched popEPSPSs).

We then went on and reversed the protocol, and started with three successive TS episodes, each separated by $5 \mathrm{~min}$, followed by a single LFS. An example of such an experiment is shown on Figure 4. After the third conditioning TS the long-term potentiation of the responses (popEPSPSs and PSAs) was at a maximum. popEPSPSs were $140 \%$ (Fig. $4 A$ ) and PSAs were $162 \%$ of control (Fig. 4B). E/S potentiation occurred and reached its maximum at the second TS. While LFS unsaturated these responses $(100 \%$ and $141 \%$ of control for popEPSPSs and PSAs, respectively) it did not change $\mathrm{E} / \mathrm{S}$ coupling. Pooled results ( $n$ $=4$ ) are presented on Figure $4 D$ and show potentiated responses $(141 \pm 12 \%$ and $162 \pm 11 \%)$ following the third TS which was reversed to $101 \pm 8 \%$ and $140 \pm 7 \%$, respectively, following the LFS. Usually, the maximum E/S potentiation was achieved after the second TS and did not change following LFS. The PSA measured following the second TS was increased by $33+11 \%$ when compared to that obtained before the conditioning stimulus (for matched popEPSPSs).

From these data it appears that whatever the pattern of the conditioning stimulus used in this study there was E/S potentia- tion. This E/S potentiation is close to saturation and once triggered can not be reversed.

\section{NMDA dependency of E/S potentiation}

LFS is known to induce a NMDA receptor-dependent synaptic LTD (Mulkey and Malenka, 1992). We thus decided to investigate whether or not the E/S potentiation observed following LFS was dependent upon the activation of NMDA receptors. Figure 5 shows an example of an experiment in which D-APV $(25 \mu \mathrm{M})$ was applied for $1 \mathrm{hr}$ in order to block the NMD $\Lambda$ component. This had no effect on the popEPSPS (100\% of control, Fig. $5 A$ ) but produced an increase of the PSA (135\% of control, Fig. $5 B$ ). As a result, a left shift was observed on the E/S curves (Fig. $5 C$ ). In the presence of D-APV, LFS resulted in short-term depression of the synaptic responses. However, LFS produced a substantial LTi of the PSAs (233\% of control). Consequently, a larger E/S potentiation was observed. In the subsequent $1.5 \mathrm{hr}$ washout of D-APV, the popEPSPSs, PSAs and the E/S coupling remained unchanged. $\Lambda$ second LFS then produced synaptic LTD (70\% of control) showing that the NMDA receptor dependence of the LTD had been restored. Likewise, PSAs were reduced to $172 \%$ of control. The E/S relationship remained unchanged following the second LFS.

Data are summarized in the histogram, Figure $5 D(n=5)$. D-APV had no effect on the popEPSPSs $(100 \pm 3 \%$ of control) but increased the PSAs (126 $\pm 9 \%$ of control). LFS in the presence of D-APV prevented synaptic LTD ( $99 \pm 6 \%$ of control) but induced LTi of the PSAs ( $212 \pm 21 \%$ of control). Following washout of the D-APV, the popEPSPs and PSAs remained unchanged ( $100 \pm 5 \%$ and $210 \pm 19 \%$ of control, respectively). A second LFS then produced synaptic LTD ( $70 \pm 12 \%$ of control) and LTd of PSAs (143 $\pm 25 \%$ of control). In all experiments LFS resulted in a massive $\mathrm{E} / \mathrm{S}$ potentiation in the presence of D-APV. The PSA measured following application of D-APV was increased by $28 \pm 16 \%$ when compared to that obtained before the application (for matched popEPSPSs) and the PSA measured following LFS was further increased by $124 \pm 32 \%$ when compared to that obtained before the conditioning stimulus. This potentiation then reached its maximum and no further shift could be seen when the ability to express LTD was restored following the washout of D-APV. These results suggest that E/S potentiation following LFS is an NMDA receptor-independent phenomenon.

\footnotetext{
Figure 1. Example of the effects of low frequency stimulation (LFS) in the Schaffer collateral/ commissural pathway of the CA1 area of the hippocampus. A, Time course of the population EPSP slope measured every $30 \mathrm{sec}$. After the establishment of a stable baseline for 10 min, LFS $(1 \mathrm{~Hz}$ for $15 \mathrm{~min})$ at the same stimulus intensity as the test was applied. After this $15 \mathrm{~min}$ the test stimuli resumed. Note that the synaptic responses were depressed. This depression was reversed by tetanic stimulation (TS, arrow) which induced stable LTP. $B$, Same as $A$ but for the population spike anplitude. Note that the amplitude is also depressed following LFS and subsequently potentiated following TS. $C$, Averages of three consecutive field population EPSPs measured before ( 1 ), after LFS (2), and after TS (3). The corresponding population spikes are shown in 4, 5 , and 6 . The times at which these traces were recorded are indicated in $A$ and $B$. D. Two popEPSPs with identical slopes are superimposed on the left. 'The corresponding PSs are shown of the right. Note that the PSA measured following LFS is greater than that obtained before the conditioning stimulus. Scales as in $C$. E, EPSP/spike (E/S) curves obtained by plotting the population spike amplitude as a function of the population EPSP slope obtained at different test stimulus intensities before (solid squares), following LFS (solid diamonds) and following TS (solid circles). As in the following figures, population EPSP slopes are expressed as a percentage of their maximum value and population spike amplitudes are expressed as a percentage of their maximum value before conditioning stimulation. Note that there is a left shift of the curve following LFS and a further one following TS. This left shift indicates E/S potentiation, that is, there is a larger potentiation of the population spike than that can be accounted for by the synaptic LTP. $F$, Summary of 10 experiments in which synaptic responses and population spike amplitudes were $66 \pm 18 \%$ and $73 \pm$ $12 \%$ of control respectively following LFS. Following TS responses were $95 \pm 21 \%$ and $112 \pm 24 \%$ of their control, respectively. As in the following figures, * indicates $p<0.0001$ and always relates to the response prior to the last conditioning stimulus. Note that the digital noise that is apparent in these figures was introduced by the plotting package.
} 
A

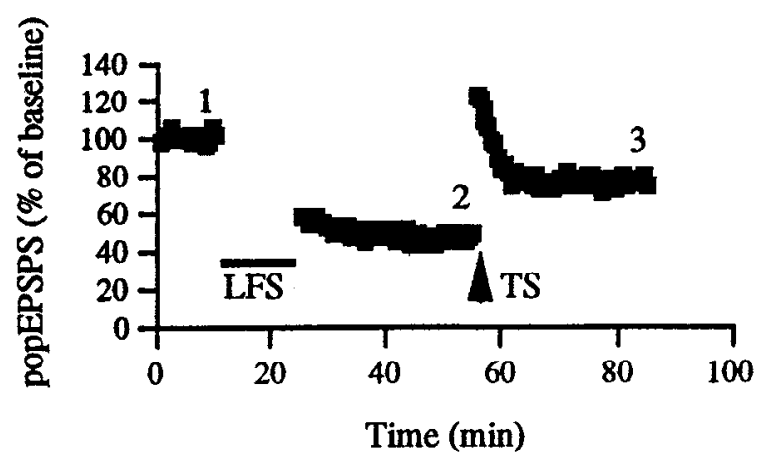

B

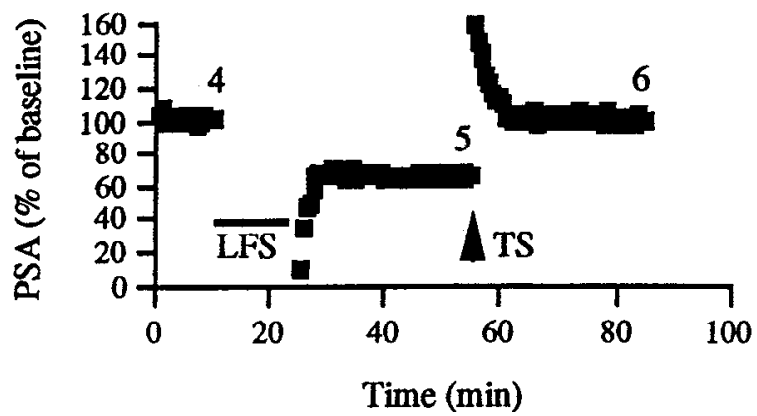

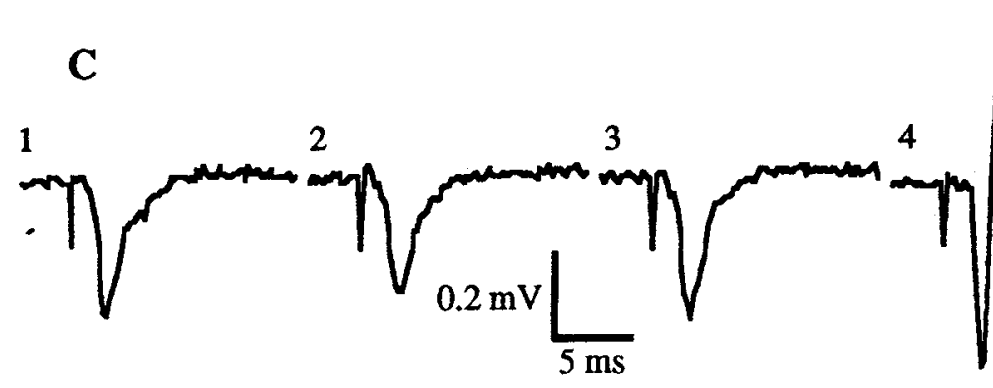

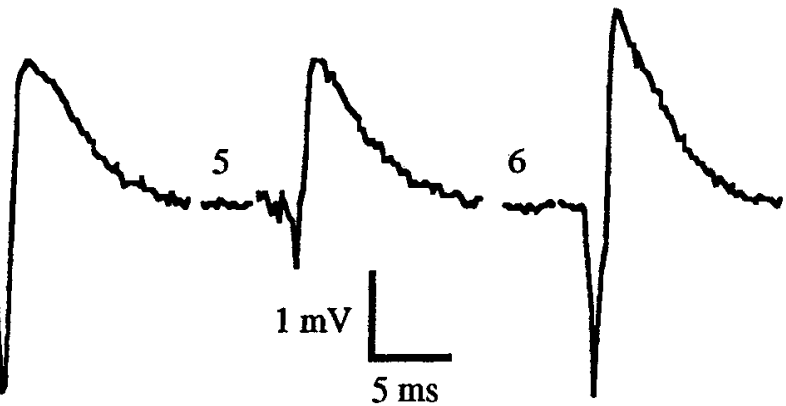

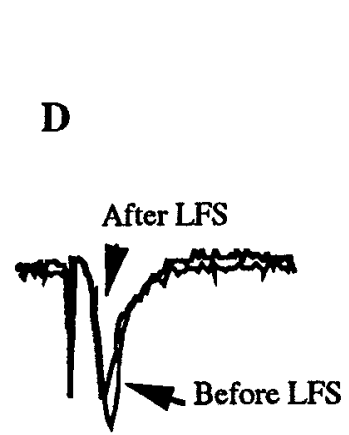

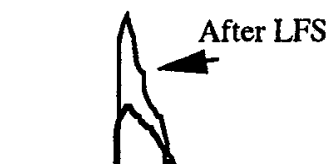

After LFS
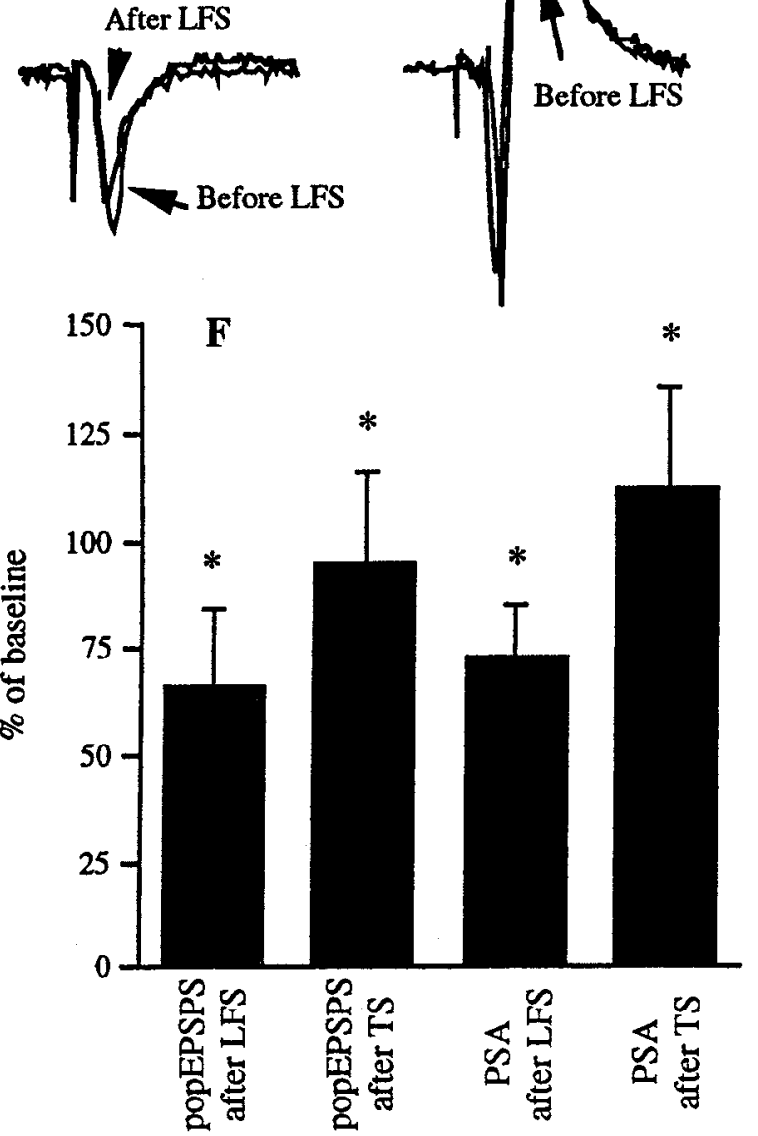

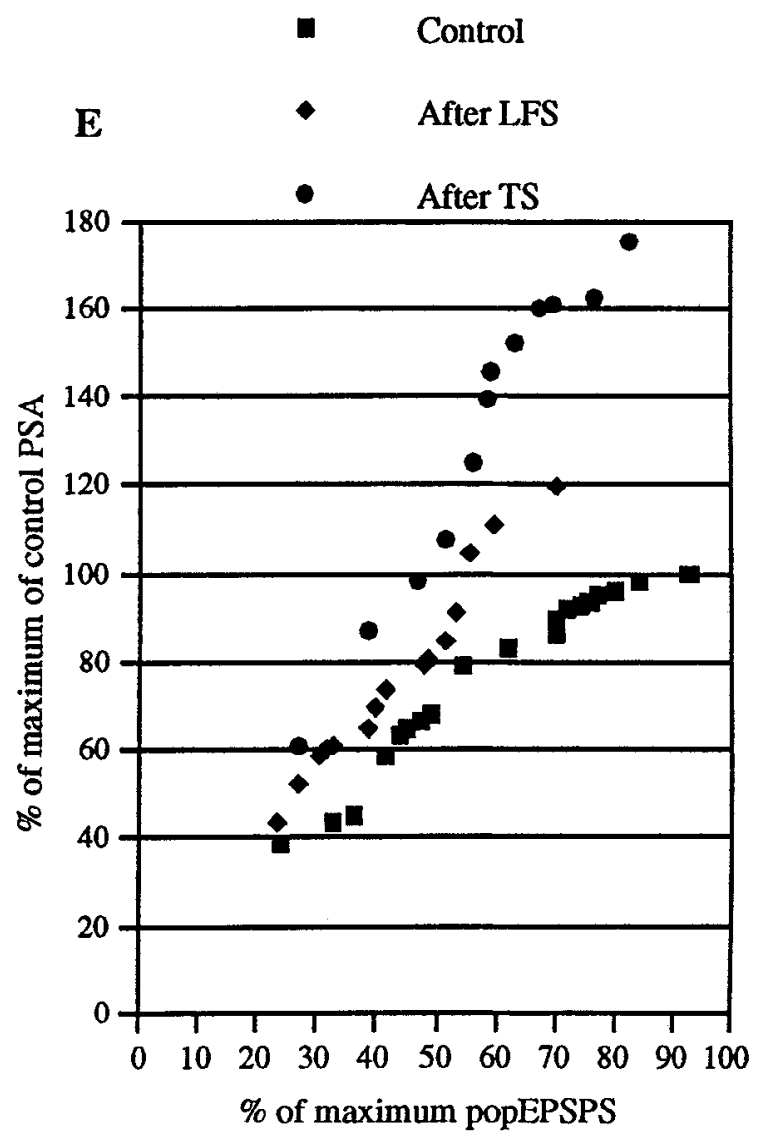



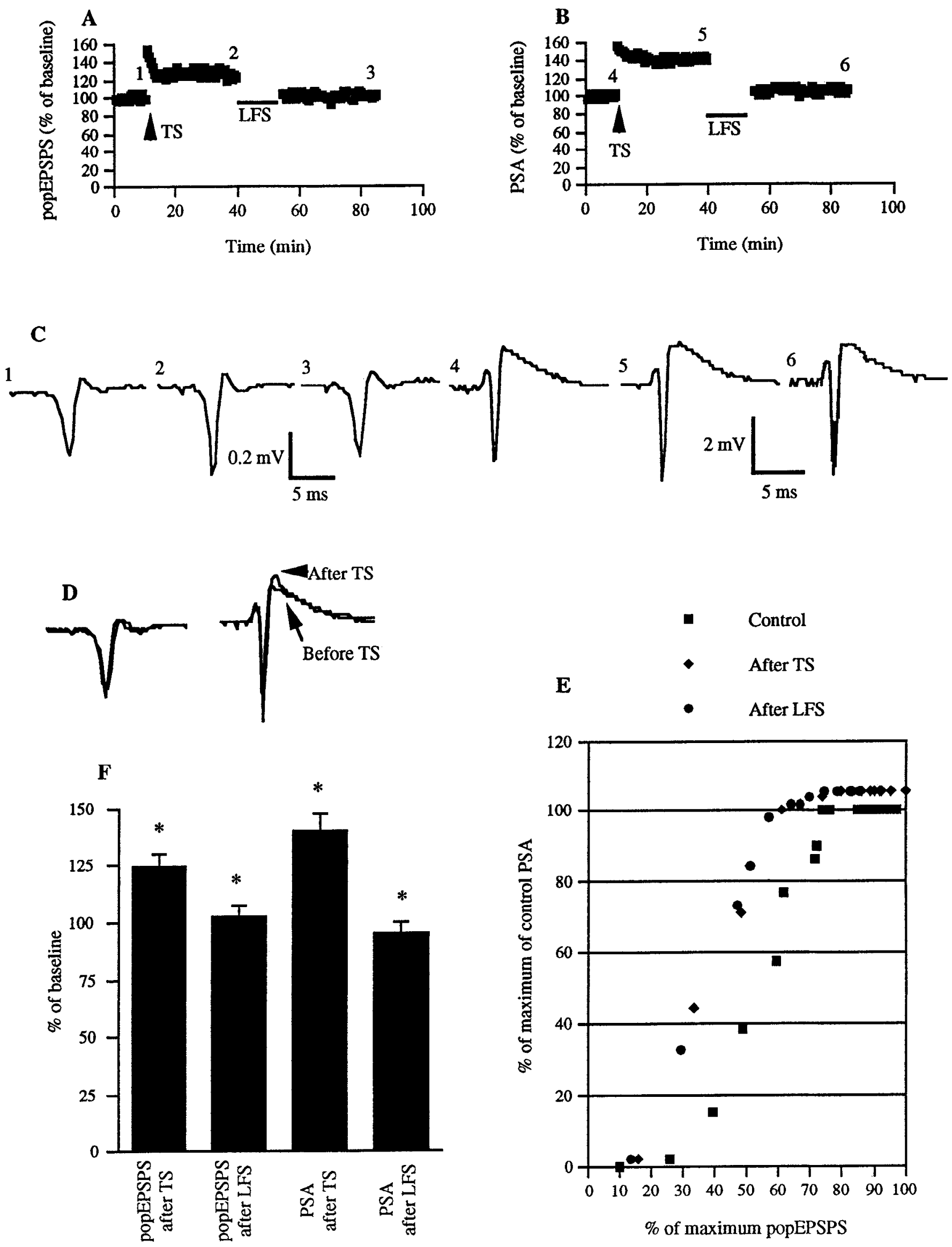

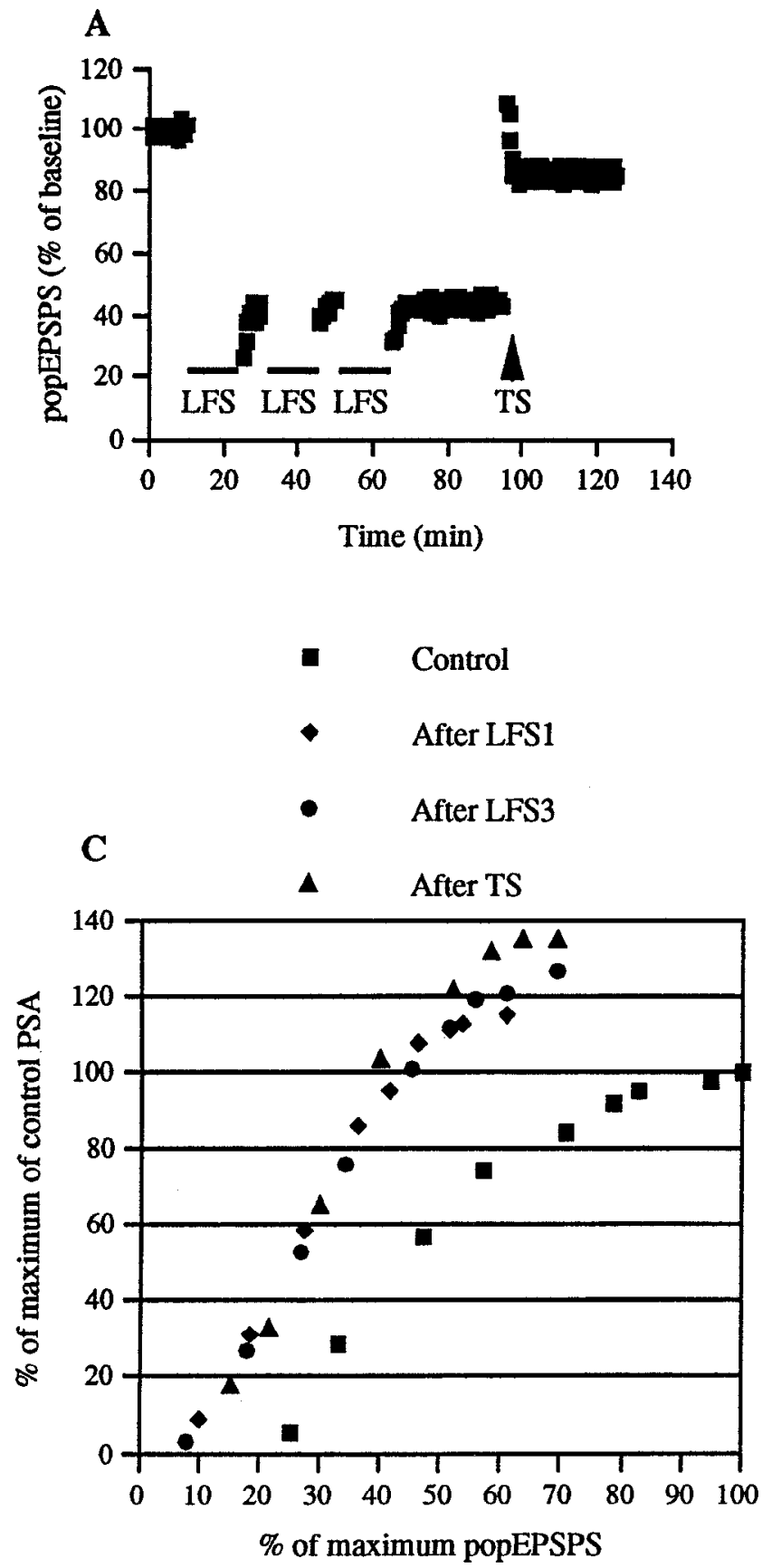
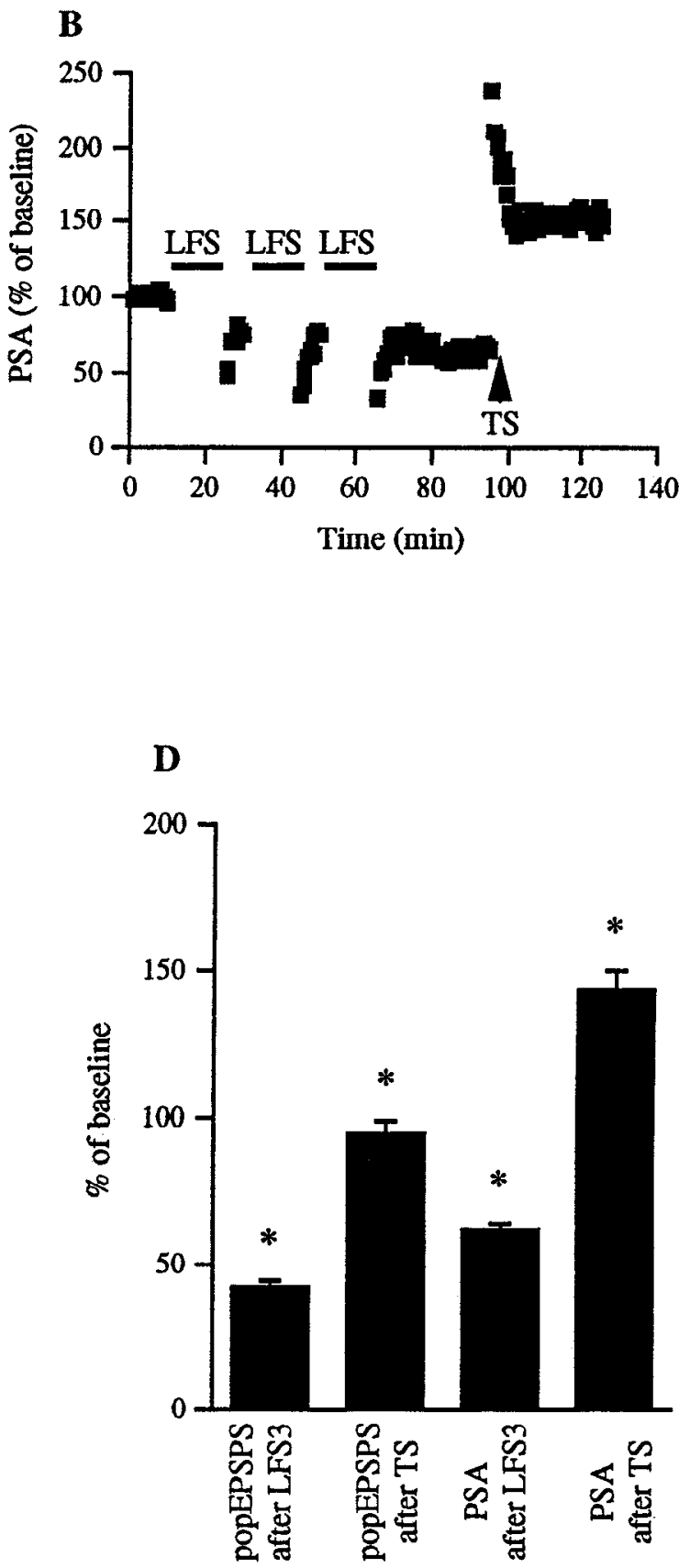

Figure 3. Effects of saturation towards depression of synapses on E/S coupling. Example of a typical experiment in which three LFS conditioning stimuli were applied at $5 \mathrm{~min}$ intervals. $A$, Time course of the population EPSP slope. Note that the synaptic response reaches a plateau following the third conditioning train ( $42 \%$ of control). Following TS (arrow) LTP could be induced but was only $85 \%$ of control. $B$, As in $A$, But for the population spike amplitude. A large depression could also be achieved (60\% of control) which was reversed following TS (150\% of control). $C$, Corresponding E/S curves hefore (solid squares), following the first IFS (solid diamonds), the third LFS (solid circles) and TS (solid triangles). Note that the left shift was maximum after the first conditioning train. $D$, Summary of four experiments in which synaptic responses and population spike amplitudes were $42 \pm 7 \%$ and $61 \pm 9 \%$ of control, respectively, following the third LFS. Following TS, responses were $94 \pm 12 \%$ and 143 $\pm 15 \%$ of control, respectively.

Figure 2. Example of an experiment showing the effects of TS followed by LFS on field potentials. TS (arrow) resulted in synaptic LTP (A) and long-term increase of the population spike amplitude $(B)$ which could be reversed following LFS. $C$, Average of three traces measured before and following TS and LFS. $D$, Two popEPSPs with identical slopes are superimposed on the left. The corresponding PSs are shown of the right. Note that the PSA measured following TS is greater than that obtained before the conditioning stimulus. Scales as in $C$. $E$, E/S curves show E/S potentiation following TS and no further changes following LFS. $F$, Summary of 10 experiments in which synaptic responses and population spike amplitudes were $124 \pm 7 \%$ and $140 \pm 12 \%$ of control, respectively, following TS. Following LFS responses were $102 \pm 6 \%$ and $95 \pm 9 \%$ of control, respectively. 
A
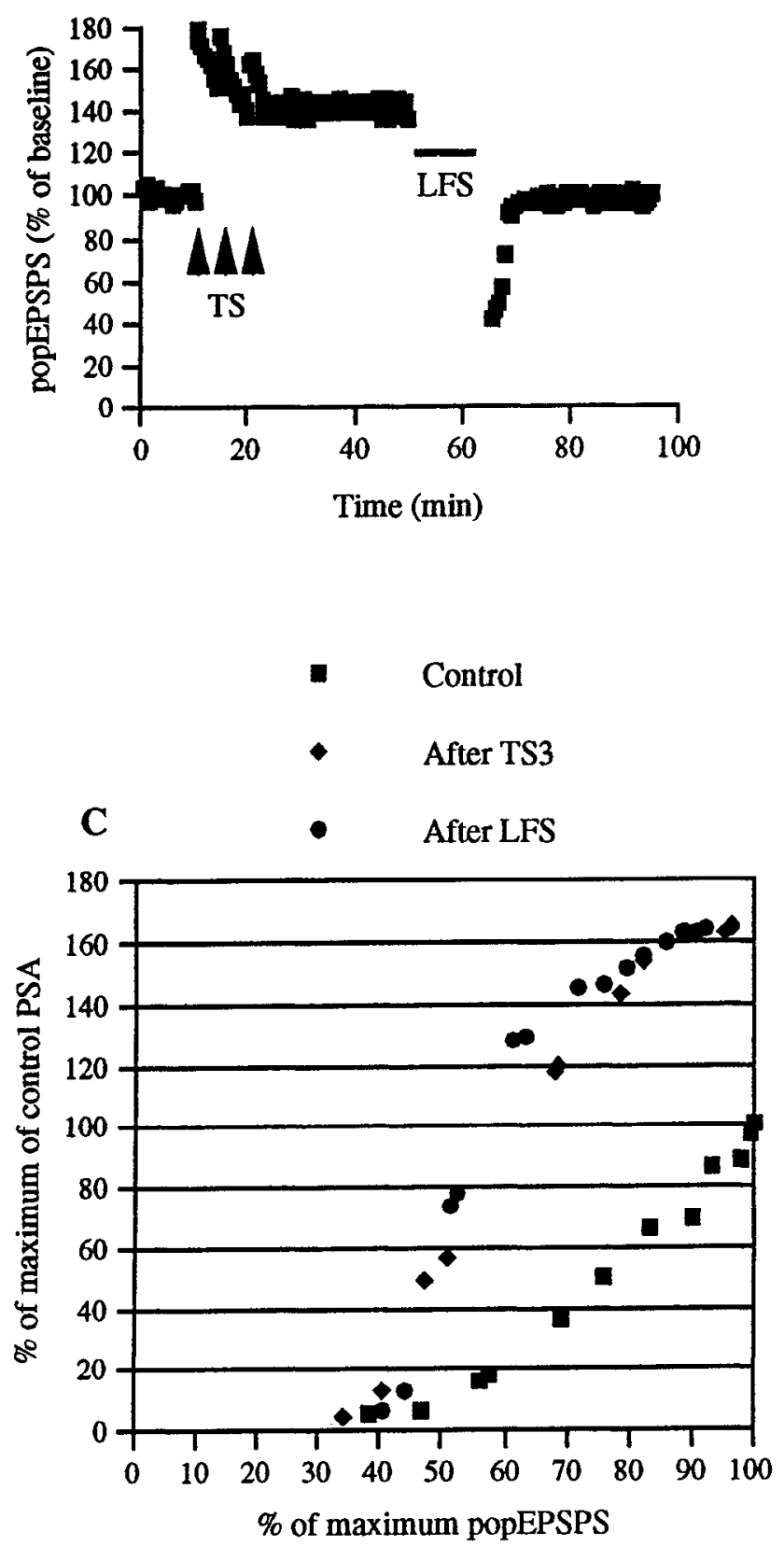

B

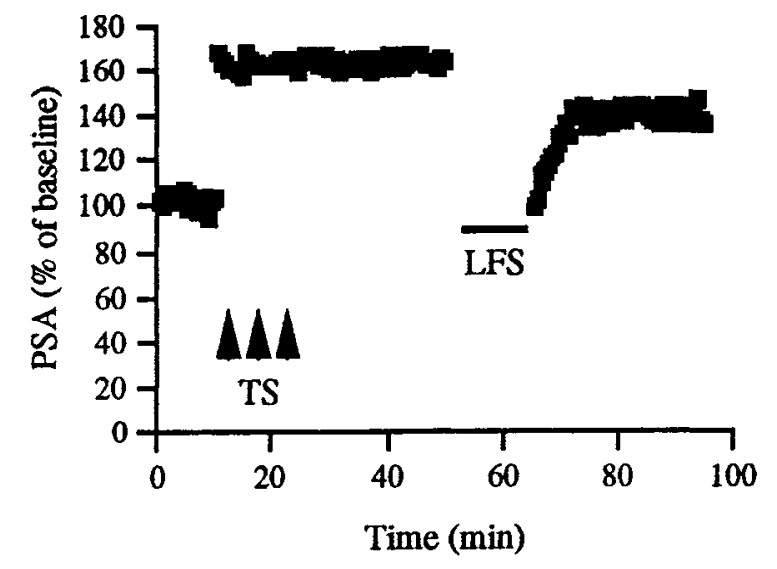

$\mathbf{D}$

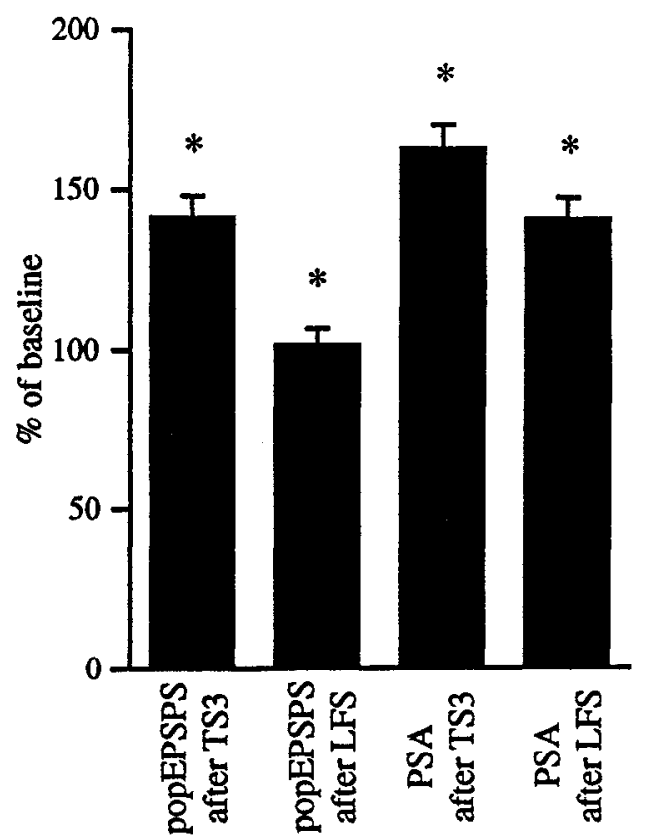

Figure 4. Same as Figure 3 but using three TS conditioning trains followed by LFS. Following the third TS the responses were saturated and this potentiation could be reversed by LFS $(A, B)$. C, As in Figure 3 the left shift was maximum following the first TS and the depression of the synaptic responses did not change the $\mathrm{E} / \mathrm{S}$ dissociation. $D$. Summary of four experiments in which synaptic responses and population spike amplitudes were $141 \pm 12 \%$ and $162 \pm 11 \%$ of control, respectively, following the third TS. Following LFS, responses were $101 \pm 8 \%$ and 140 $\pm 7 \%$ of control, respectively.

\section{Discussion}

In this study we have investigated the E/S coupling following LFS. The major findings are, first, that LFS increases the probability of synchronous discharge of the neurons. However, this increase was not sufficient to override the effects of the decreased excitatory drive following LFS. Second, the E/S potentiation usually reaches its maximum effect after the first conditioning stimulus. Third, the saturation (maximal or minimal) of the synaptic responses also produces a non reversible E/S potentiation. Finally, the LFS-induced E/S potentiation in the CA1 area is not dependent upon the activation of the NMDA receptors.

\section{Possible mechanisms for E/S dissociation}

Two hypothesis have been proposed to explain E/S potentiation following TS. The first of these involves the inhibitory network: if the excitatory synapses on the inhibitory interneurons are less potentiated than the excitatory synapses on the pyramidal cells and/or if the inhibitory synapses on the pyramidal cells are depressed following TS, then E/S potentiation may occur (Wilson, 

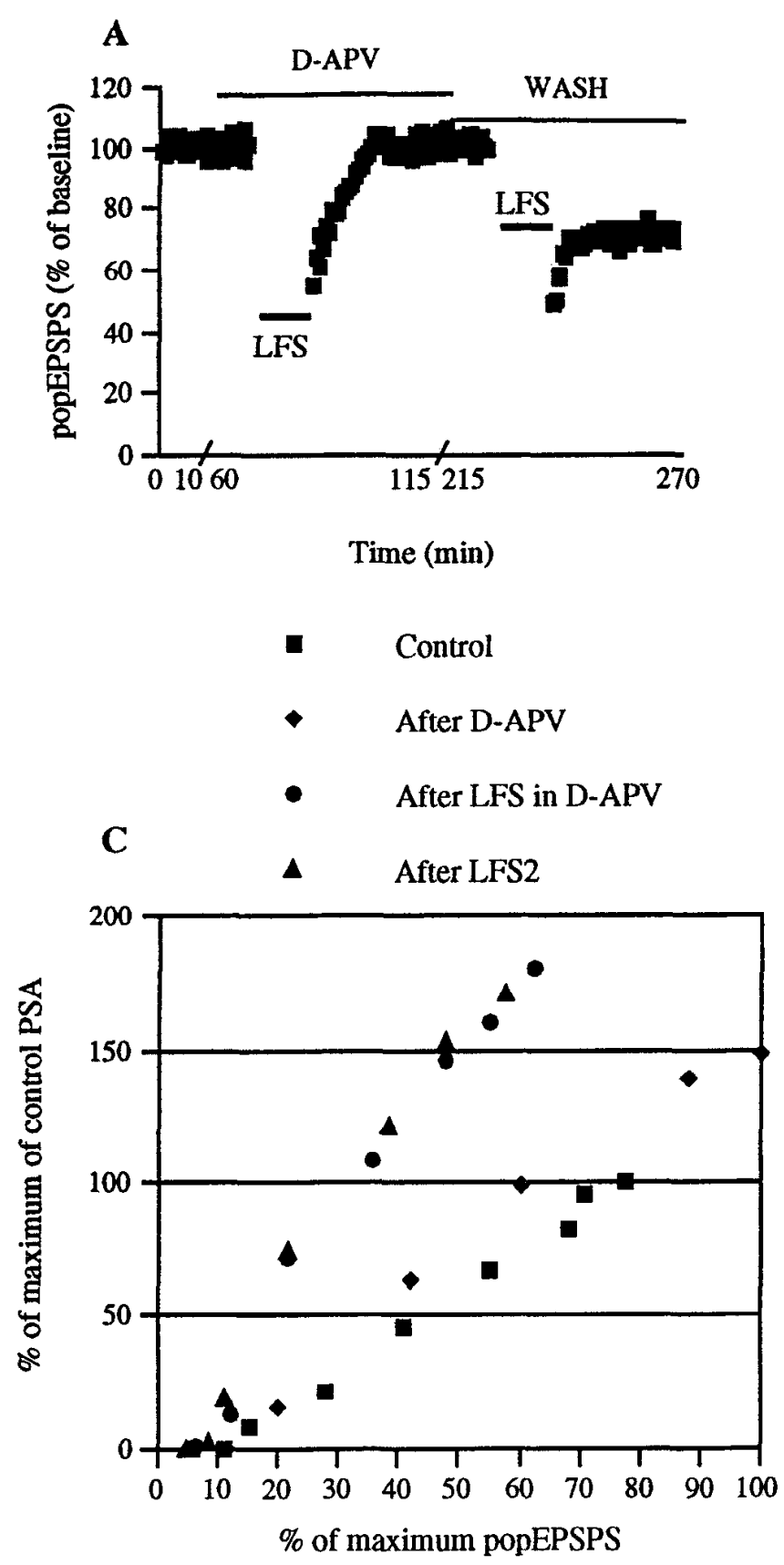
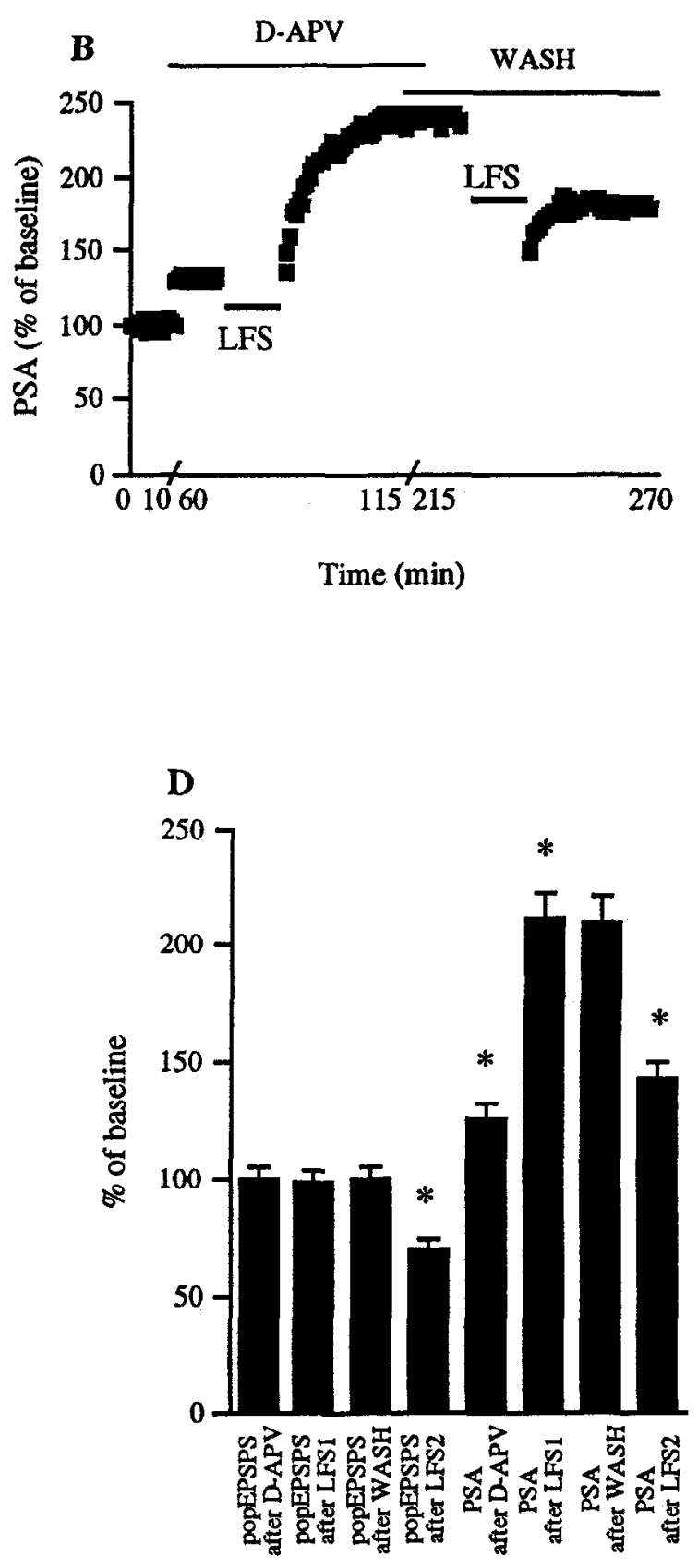

Figure 5. E/S potentiation following LFS does not require the activation of NMDA receptors. Example of an experiment in which D-APV (25 $\mu M)$ was applied for an hour in order to block NMDA receptor-mediated responses. D-APV had no effect on the population EPSP slope ( $A$ ) but increased the population spike amplitude $(B)$. In the presence of D-APV, LFS resulted in a transient depression of the population EPSP slope but induced a dramatic long-term increase of the population spike amplitude. Following washout of D-APV the responses remained unchanged. Following a second LFS synaptic LTD was induced and population spike amplitudes were depressed. Note that the time axis has been truncated for clarity. Thus, the values obtained during the hour long of application of D-APV and the hour and a half long of its washout are not included. $C$, Corresponding E/S curves before (solid squares), following application of D-APV (solid diamonds), LFS in the presence of D-APV (solid circles) and following the second LFS after the washout of D-APV (solid triangles). Note that there is a left shift after the application of D-APV. Following LFS there is a larger left shift indicating an important E/S potentiation. This potentiation was unchanged by the second LFS. $D$, Summary of five experiments in which synaptic responses and population spike amplitudes were $100 \pm 3 \%$ and $126 \pm 9 \%$ of control, respectively, following the application of D-APV. Responses were $99 \pm 6 \%$ and $212 \pm 21 \%$ of control, respectively, following the first LFS; $100 \pm 5 \%$ and $210 \pm 19 \%$ of control, respectively, following washout of D-APV; and $70 \pm 12 \%$ and $143 \pm 25 \%$ of control, respectively, following the second LFS.

1981; Wilson et al., 1981; Abraham et al., 1987; Kairiss et al., 1987; Chavez-Noriega et al., 1989, 1990; Hess and Gustafsson, 1990; Tomasulo et al., 1991; Tomasulo and Ramirez, 1993). The alternative hypothesis is a modification of the firing threshold of the neurons (Schwartzkroin and Prince, 1980; Taube and
Schwartzkroin, 1988a,b; Hess and Gustafsson, 1990). This issue is still controversial and would require the use of an intracellular protocol, in which one monitored both isolated IPSPS as well as the action potential threshold, to resolve. In this study we have used extracellular recording protocols, which have the consid- 
erable advantage of providing us with a better insight into the collective behaviour of the cell population. Furthermore, it allowed us to produce comparative E/S curves. However, it provides us with limited access to the inhibitory interneurons or the modification of the firing threshold. Another alternative would be to use of a hippocampal preparation devoid of inhibition such as the kainic acid lesioned rat hippocampus (Ashwood et al., 1986) where $\mathrm{E} / \mathrm{S}$ dissociation is dependent on the change of the firing threshold of the cells (Bernard and Wheal, 1995). Indeed, in this preparation LFS produced an NMDA independent E/S potentiation (Bernard and Wheal, 1994).

The protocols used in this study did not permit us to investigate the input specificity of $F / S$ dissociation. However, this property will need to be investigated using intracellular techniques.

\section{Properties of E/S potentiation}

We have shown that E/S coupling was easily saturated and could not be reversed with the conditioning stimuli used in this study. However when E/S potentiation was maximum, the synaptic responses could still be modified. This result suggests that there is little or no interaction between synaptic LTP (or LTD) and $\mathrm{E} / \mathrm{S}$ dissociation. It has been suggested that it is the calcium entry through the NMDA channels which controls the expression of LTP or LTD (Mulkey and Malenka, 1992). We have shown in this study that $E / S$ potentiation occurs even when NMDA receptors are blocked. We thus suggest that the mechanisms responsible for $\mathrm{E} / \mathrm{S}$ modification are independent (at least partly) from those involved in LTP and LTD.

An additional phenomenon following the application of the NMDA receptor antagonist D-APV was the clear increase of the PSA whilst. the popEPSPS was unchanged. We interpret this result as a direct decrease of the excitatory drive on the inhibitory interneurons. In CA1 the NMDA receptor-mediated component of the synaptic drive onto inhibitory interneurons is significantly larger (Alger, 1984; Capek and Esplin, 1991) than that seen on CA1 pyramidal cells (Collingridge et al., 1983; Coan and Collingridge, 1985; Herron et al., 1985; Andreasen et al., 1988; Fletcher et al., 1988; Blake et al., 1989). Following the application of D-APV, the number of interneurons activated will be decreased, and consequently, the firing probability of the CAI pyramidal cells will be increased. However, in picrotoxin treated slices APV $(50 \mu \mathrm{M})$ was shown to produce E/S depression (Sah et al., 1989) which was due to the presence of endogenous glutamate acting directly on NMDA receptors. Here, we suggest that the role of NMDA receptors on the interneurons dominates over the blockade of tonic activation and thus results in $\mathrm{E} / \mathrm{S}$ potentiation. Indeed, the use of picrotoxin or bicuculline alone is known to produce a massive E/S potentiation (Kairiss et al., 1987; Abraham et al., 1987; Chavez-Noriega et al., 1989; Hess and Gustafsson, 1990; Tomasulo et al., 1991). In such preparations TS resulted in a further E/S potentiation (Hess and Gustafsson, 1990).

An intriguing phenomenon is summarized on Figure 4 where LFS in the presence of D-APV induced a massive E/S potentiation. We suggest that the activation of the NMDA receptors during a conditioning stimulus prevents the full expression of $\mathrm{E} / \mathrm{S}$ potentiation, either by downregulating the modification of the action potential threshold or by preventing a too large depression of excitatory synapses on interneurons. Furthermore, this mechanism is an intrinsic property of the CA1 area since when NMDA receptor mechanisms are suppressed we obtain a clearer indication of the dynamic range of this potentiation. Interestingly, when NMDA receptors are again functional the massive E/S potentiation remains unaffected.

The firing threshold of the cells may be linked to the mechanism of E/S dissociation. An increase in the density of voltagesensitive calcium channels (Taube and Schwartzkroin, 1988a,b; Wathey et al., 1992) will decrease the firing threshold and produce E/S potentiation. Additionally, E/S dissociation may depend upon the activation of metabotropic receptors or second messengers systems which are involved in LTP and LTD (Mulkey and Malenka, 1992; Bashir et al., 1993a,b; Bliss and Collingridge, 1993; Mulkey et al., 1993).

In conclusion, we have shown that the effects of synaptic LTD are partly counterbalanced by $\mathrm{E} / \mathrm{S}$ potentiation. As a consequence the relationship of the $\mathrm{E} / \mathrm{S}$ potentiation with respect to synaptic LTD, may be one of modulation rather than antagonism. This is extremely interesting from the neuronal network point of view since the E/S potentiation was not predicted from the earlier reports on synaptic depression induced by LFS. To quote Malenka we may say that "LTD is not so depressing after all" (Malenka, 1993). Furthermore, the E/S potentiation is independent of the activation of NMDA receptors. However, the fact that the firing probability can be changed in association with synaptic LTP and LTD provides a further parameter controlling the plasticity of this neuronal network. Finally, we would like to stress again that the modification of the synapses is one of the first steps in the cascade of processes which control information processing. Furthermore, the role of the integration of inhibition and firing threshold should not be underestimated.

\section{References}

Abraham W, Gustafsson B, Wigstrom H (1987) Long-term potentiation involves enhanced synaptic excitation relative to synaptic inhibition in guinea-pig hippocampus. J Physiol (Lond) 394:367-380.

Alger B (1984) Characteristics of a slow hyperpolarizing synaptic potential in rat hippocampal cells in vitro. J Neurophysiol 52:892-910.

Andersen P, Sundberg S, Sveen O, Swann J, Wigstrom H (1980) Possible mechanisms for long-lasting potentiation of synaptic transmission in hippocampal slices from guinea-pigs. J Physiol (Lond) 302: 463-482.

Andreasen M, Lambert J, Jensen M (1988) Direct demonstrations of an $N$-methyl-M-aspartate receptor mediated component of excitatory synaptic transmission in area CA1 of the hippocampus. Neurosci Lett 93:61-66.

Ashwood TJ, Lancaster B, Wheal HV (1986) Intracellular electrophysiology of CA1 pyramidal neurones in slices of the kainic acid lesioned hippocampus. Exp Brain Res 62:189-198.

Bashir ZI, Bortolotto ZA, Davies CH, Berretta N, Irving AJ, Seal AJ, Henley JM, Jane DE, Watkins JC, Collingridge GL (1993a) Induction of LTP in the hippocampus needs synaptic activation of glutamate metabotropic receptors. Nature 363:347-350.

Bashir ZI, Jane DE, Sunter DC, Watkins JC, Collingridge GL (1993b) Metabotropic glutamate receptors contribute to the induction of longterm depression in the CA1 region of the hippocampus. Eur J Pharmacol 239:265-266.

Bernard C, Wheal HV (1994) Dynamic properties of synaptic responses and firing of CA1 pyramidal cclls in the kainic acid lesioned hippocampus. Brain Res Assoc Abstr 11:29.

Bernard C, Wheal HV (1995) Simultaneous expression of EPSP/spike potentiation and EPSP/spike depression in the hippocampus. Neuroscience 67:73-82.

Blake J, Yates R, Collingridge G (1989) 6-Cyano-7-nitroquinoxaline2,3-dione as an excitatory amino acid antagonist in area CA1 of the rat hippocampus. Br J Pharmacol 97:71-96.

Bliss T, Collingridge G (1993) A synaptic model of memory: longterm potentiation in the hippocampus. Nature 361:31-39.

Capek R, Esplin B (1991) Attenuation of hippocampal inhibition by a NMDA ( $N$-methyl-M-aspartate) receptor antagonist. Neurosci Lett 129:145-148. 
Chavez-Noriega L, Bliss T, Halliwell J (1989) The epsp-spike (E-S) component of long-term potentiation in the rat hippocampal slice is modulated by GABAergic but not cholinergic mechanisms. Neurosci Lett 104:58-64.

Chavez-Noriega L, Halliwell J, Bliss T (1990) A decrease in firing threshold observed after induction of the EPSP-spike (E-S) component of long-term potentiation in rat hippocampal slices. Exp Brain Res 79:633-641.

Coan E, Collingridge $\mathrm{G}$ (1985) Magnesium ions block an $N$-methyl$\mathrm{M}$-aspartate receptor-mediated component of synaptic transmission in rat hippocampus. Neurosci Lett 53:21-26.

Collingridge G, Kehl S, McLennan H (1983) Excitatory amino acids in synaptic transmission in the Schaffer collateral-commissural pathway of the rat hippocampus. J Physiol (Lond) 334:33-46.

Douglas R, Goddard G (1975) Long-term potentiation of the perforant path-granule cell synapse in the rat hippocampus. Brain Res 86:205215

Dudeck S, Bear M (1992) Homosynaptic long-term depression in area CA1 of hippocampus and effects of NMDA receptor blockade. Proc Natl Acad Sci USA 89:4363-4367.

Dudek SM, Bear MF (1993) Bidirectional long-term modification of synaptic effectiveness in the adult and immature hippocampus. J Neurosci 13:2910-2918.

Fletcher E, Martin D, Aram J, Lodge D, Honore T (1988) Quinoxaline diones selectively block quisqualate and kainate receptors and synaptic events in the rat neocortex, hippocampus and frog spinal cord in vitro. Br J Pharmacol 95:585-597.

Frey U, Krug M, Teymann K, Matthies H (1988) Anisomycin, an inhibitor of protein synthesis, blocks late phases of LTP phenomena in the hippocampal CA1 region in vitro. Brain Res 452:57-65.

Guo L, Chai H, Xie Y (1992) Observations of synaptic efficacy and paired-pulse facilitation in area CAl of hippocampal slices from coriaria lactone-kindled rats. Brain Res 572:269-272.

Hebb D (1949) The organization of behavior. New York: Wiley.

Herron C, Williamson R, Collingridge G (1985) A selective $N$-methyl$\mathrm{M}$-aspartate antagonist depresses epileptiform activity in rat hippocampal slices. Neurosci Lett 61:255-260.

Hess G, Gustafsson B (1990) Changes in field excitatory postsynaptic potential shape induced by tetanization in the CA1 region of the guinea-pig hippocampal slice. Neuroscience 37:61-69.

Ito M (1989) Long-term depression. Annu Rev Neurosci 12:85-102.

Kairiss E, Abraham W, Bilkey D, Goddard G (1987) Field potential evidence for long-term potentiation of feed-forward inhibition in the rat dentate gyrus. Brain Res 401:87 -94.

Malenka RC (1993) Long-term depression: not so depressing after all. Proc Natl Acad Sci USA 90:3121-3123.

Mulkey RM, Malenka RC (1992) Mechanisms underlying induction of homosynaptic long-term depression in area CAl of the hippocampus. Neuron 9:967-975.

Mulkey RM, Herron CE, Malenka RC (1993) An essential role for protein phosphatases in hippocampal long-term depression. Science 261:1051-1055.

Keymann K, Matthies H, Schulzeck K (1989) N-Methyl-D-asparate receptor activation is required for the induction of both early and late phases of long-term potentiation in rat hippocampal slices. Neurosci Lett 96:96-101.

Sah P, Hestrin S, Nicoll R (1989) Tonic activation of NMDA receptors by ambient glutamate enhances excitability of neurons. Science 246 : 815-817.

Schwartzkroin P, Prince D (1980) Changes in excitatory and inhibitory synaptic potentials leading to epileptogenic activity. Brain Res 183: 169-181.

Taube J, Schwartzkroin P (1988a) Mechanism of long-term potentiation: a current-source density analysis. J Neurosci $8: 1645-1655$.

Taube J, Schwartzkroin P (1988b) Mechanisms of long-term potentiation: EPSP/spike dissociation, intradendritic recordings, and glutamatc sensitivity. J Neurosci 8:1632-1644.

Tomasulo R, Ramirez J (1993) Activity-mediated changes in feed-forward inhibition in the dendate commissural pathway: relationship to EPSP/spike dissociation in the converging perforant path. J Neurosci 69:165-173.

Tomasulo R, Levy W, Steward O (1991) LTP-associated EPSP/spike dissociation in the dendate gyrus: GABAergic and non-GABAergic components. Brain Res 561:27-34.

Wathey J, Lytton W, Jester J, Sejnowski T (1992) Computer simulations of EPSP-spike (E-S) potentiation in hippocampal CA1 pyramidal cells. J Neurosci 12:607-618.

Wilson R (1981) Changes in translation of synaptic excitation to dendate granule cell discharge accompanying long-term potentiation. I. Differences between normal and reinnervated dendate gyrus. J Neurophysiol 46:324-338.

Wilson R, Levy W, Steward O (1981) Changes in translation of synaptic excitation to dendate granule cell discharge accompanying longterm potentiation. II. An evaluation of mechanisms utilizing dendate gyrus dually innervated by surviving ipsilateral and sprouted crossed temporodendate inputs. J Neurophysiol 46:339-355. 